\title{
On the utilization of social animals as a model for social robotics
}

\section{Ádám Miklósi * and Márta Gácsi}

Department of Ethology, Eötvös University, Budapest, Hungary

Edited by:

Thomas Bugnyar, Universität Wien,

Austria

Reviewed by:

Jennifer Vonk, University of Southern

Mississippi, USA

Francine L. Dolins, University of

Michigan-Dearborn, USA

Mathias Osvath, Lund University,

Sweden

*Correspondence:

Ádám Miklósi, Department of

Ethology, Eötvös University, H-1117,

Pázmány P. s. 1/c, Budapest, Hungary

e-mail:amiklosi62@gmail.com
Social robotics is a thriving field in building artificial agents. The possibility to construct agents that can engage in meaningful social interaction with humans presents new challenges for engineers. In general, social robotics has been inspired primarily by psychologists with the aim of building human-like robots. Only a small subcategory of "companion robots" (also referred to as robotic pets) was built to mimic animals. In this opinion essay we argue that all social robots should be seen as companions and more conceptual emphasis should be put on the inter-specific interaction between humans and social robots. This view is underlined by the means of an ethological analysis and critical evaluation of present day companion robots. We suggest that human-animal interaction provides a rich source of knowledge for designing social robots that are able to interact with humans under a wide range of conditions.

Keywords: social robotics, ethology, human-animal interaction, dogs, inter-specific interaction

\section{INTRODUCTION}

In the last few years there has been a huge interest in building robots that interact in a socially acceptable way with humans. In this opinion essay we suggest that this field of social robotics should draw more on the insights of ethology. We identify problems in social robotics from an ethological point of view, and will argue that functional considerations in construction of social robots are vital. Present day social robots have a range of limitations both in hardware and in software which constrain their utility and believability. A closer look at human-animal interaction, especially the detailed investigation of the social relationship between humans and dogs, may provide important insights for social robotics.

\section{THE ETHOLOGY OF SOCIAL BEHAVIOR}

Székely et al. (2010, p. 1) define social behavior as "activities among members of the same species that have fitness consequences for both the focal individual and other individuals in the group." This behavioral ecological approach is important because it stresses the fact that social behaviors have a function, that is, they have been evolved specifically to contribute to the survival of the individual. This notion is often neglected when researchers focus exclusively on the social behavior of humans in its present context, and interpret human social behavior in terms of mechanisms that function in order to maintain our society. Such an anthropocentric approach actually neglects the fact that during evolution social behavior has evolved many times independently and has been under strong selective pressures. The complex nature of human social behavior, which is familiar to all of us, masks the much less known social activities of other species in nature. For example, sophisticated social interactions between conspecifics are not only present in our closest relatives (apes) but also in such divergent groups of animals such as ants and dolphins. At the functional level social behavior serves particular goals, like finding a suitable mate, evading predator attack, cooperating in the acquisition of food etc. This means that one may find behavioral mechanisms that have evolved in different species but share some commonalities because of ancient homologies or convergent evolutionary processes. Social behavior can be broken down into simple units that may correspond across species (e.g., Fitch et al., 2010). For example, during communication animals utilize a set of species-specific behaviors having been selected for the function to exert an effect on the other individual. Naturally, animals differ in the behavioral manifestation of these communicative signals but more closely related species or species living in the same environment may overlap in the type and form of signals used. Thus we advance the argument that social behavior (both non-human and human) has common foundations in terms of behavioral mechanisms which, however, are under selection in particular ecological conditions.

\section{SOCIAL ROBOTICS}

Social robotics is a rapidly emerging field aiming to design robots that can be immersed in human social networks and are able to interact with humans in a meaningful way (Fong et al., 2003; Dautenhahn, 2007). It is generally expected that in the not-too-distant future such robots will play an important role in assisting humans in various tasks. Whilst ethological research uncovers a broad perspective of social behavior in living beings (see above), main stream social robotics is focused overwhelmingly on producing humanlike social creatures. This situation is understandable and follows from the above definition of social behavior. It is also not surprising that psychological theories play a major role this field. It is implicitly assumed that in the case of social interactions, humans should show strong preference toward those who are like them. A few years ago Fong et al. (2003) described the main features of social robots in terms of their interaction with humans. They noted that such robots need to be relying on humans' tendency to anthropomorphise, have to be reactive to the human behavior and, at the 
same time, able to initiate social interactions with humans. More precisely, Fong et al. (2003) listed some "human-like" behavioral and cognitive features that such socially interactive robots should possess. These include perception and expression of emotions, high-level communication skills, recognition of and establishment of social relationship with humans, using human-like behaviors (e.g., gesturing) and showing features of personality. In summary, according to these authors socially interactive robots that are successfully accepted/adopted by human communities should show (and/or develop) human-like social competencies. It is important to note that present day robots are light years away from this state.

Recent years of research seem to have mirrored these ideas and wishes quite well. There has been a strong effort to produce a range of human-like robots (so called humanoids, androids, and geminoids, for example see MacDorman and Ishiguro, 2006; Kanda et al., 2009). The designers of these robots place usually particular emphasis on the human-likeness both in terms of embodiment and behavior. Humanoid robots reflect the human basic anatomy and posture (upright standing position on legs, having two arms with hands and fingers and face) but have a machine-like appearance, whilst androids try to enhance the similarity to humans by covering the robot with "skin-like" material, and aiming for a perfect copy of bodily details (e.g., adding eyelids, etc.). The final stage of such robot building involves the geminoids which are copies of living humans (e.g., Becker-Asano et al., 2010). In addition there are robots with mixed features, such as building an upper human torso on a rolling robotic surface.

\section{ON THE CHARACTERIZATION OF COMPANION ROBOTS}

The English word "companion" originates from the Latin word that refers to people eating together ("com" - with and "panis" bread). It is also used in many languages, for example, in German ("Kumpan"), in Italian ("accompagnatore"), in French ("compagnon") with similar meanings, like a friend, a helper or somebody who is frequently in the company of, associates with, or accompanies another. In German the word "Brotgenosse" ("bread-companion") exists also. Thus "companionship" may refer to a wide range of relationships that emerge through "just" enjoying each others' company or working together in a group ("company").

It is difficult to find out how this word has become popular in social robotics but some may have felt that this term refers to a wide scale of social relationships (see note). At one end friends could be described as "companions," but people at workplace with whom one may occasionally have lunch or small talks could be also regarded as "companions." This approach is underlined by a recent book on this topic (Wills, 2010) in which a wide range of companions are described and analyzed from a philosophical, psychological, etc. point of view often in the absence of clear functional definitions on utility.

From our perspective it is important to distinguish between a socially interactive robot and a robotic companion. The former term emphasises specific behavioral skills of a robot, that is, it is able to interact with humans under some specific conditions. However, the second term refers to a functional category, which however, is quite "fuzzy," as indicated above. A lot of problems arise when people (researchers) assume that any behavioral mechanism in place will automatically ensure the emergence of a function, for example, just because a robot is able to "talk" it will automatically have a function in the human social environment. This is probably typical in the case of devices (e.g., mobile phones) that are able to speak (a few words or sentences) without actually understanding anything. In natural systems such interactive communication skills are mostly symmetric, that is, senders and receivers are interchangeable in their roles.

In ethology there has been a long tradition to separate functional and mechanistic explanations of behavior. In the present analysis we aim for the same distinction. First, one should clarify the function of social robots, or more particularly the function of companion robots. Importantly, the better one can define the function, the more likely the appropriate mechanism is discovered (ethology) or employed (engineering).

So one may ask "Why do robots need to behave socially toward humans?" The answer to this question takes two forms. First, one should define clearly the function or "uses" of the robot and also specify quantitative (measurable) benchmarks that are useful in revealing whether the expected function has been achieved (e.g., Kahn et al., 2007). Although there have been only a few attempts to define the functions of companion robots, it seems inescapable to come up with a functional definition of a companion before such agents are constructed. More importantly those functions should be formulated in relation to the present day technology, that is, no more complex function should be targeted than what can be supported reliably by present day technology. Thus, for example, it is somewhat unfortunate to define the functions of a companion robot broadly as "personal conversationalists" given the limitations of linguistic skills of artificial agents (Wills, 2010), or refer to them as "entertainers" or "assistants" when the technology is not yet ready for such functions.

It is also important to note that if we accept that "companionship" covers a broad range of social relationships then it may be useful to regard all social robots as companions with the level or complexity of the social behavior depending on the function of that companion. Functional categories of companionship should form a continuum along the dimension of "social robots." For example, different social behavior is expected from a robot that has a "cleaning" function in a hospital compared to a robot that assists in carrying patients to different departments.

In line with the above discussion the actual social behavior of the robotic companion should depend on the assumed function. This is typically a mechanistic problem in the sense that one may ask what kind of social behaviors are needed to support the function taking into account the embodiment and technological limitations. It has been noted with reference to natural systems that social cognition and skills may be constrained by the actual embodiment of the species (Barrett et al., 2007), and similar logic may be applied here.

As we will see below, researchers or engineers use a wide range of mechanisms for supporting assumed functions of companion robots. These mechanisms involve two broad categories: embodiment and behavior. The former is often utilized in order to evoke some primary social response from the human, the later supports a flexible, proactive and reactive interaction between the robot and the human. 
In nature evolution ensures relatively close correspondence between function and mechanisms, that is, the function will constrain the mechanisms (e.g., nocturnal predators need to see in darkness) and useless or expensive mechanisms will be selected against (e.g., blind mole rat has no functional eyes). In social robotics this evolutionary concept is often referred to as believability (see an extended discussion on this issue in Rose et al., 2010), which in practical sense means that a robot should act in line with the expectancies invited by it or alternatively it should not give the impression of having higher capacities than it has in reality. This may be called also the parsimony principle of robotics. For example, if a robot has two human arm-like limbs hanging from the shoulder then it should be able to use them functionally. This principle seems to be violated by Maggie robot (see Table 1). Constructors of companion robots have, however, an advantage over evolution because they can use a mixture of embodiments and behaviors for their agents. For example, the social behavior of any robot can be enhanced by adding some linguistic skills, independently of the actual embodiment of the robot. This could be advantageous because evolution made humans highly attracted to "anything that speaks." So if the function of the companion presumes complex social skills, adding linguistic abilities ensures high levels of sociality. However, such features do come at a cost because companions that speak but lack corresponding comprehension may be not suitable for complex social interaction with humans. In contrast they could become annoying and disappointing also (decreasing believability). So constructors should aim for a closer correspondence between output and input capacities (semantic symmetricity principle).

Looking for functional analogies may offer a way out of this situation in which neither the function nor the mechanisms can be defined easily. Although there have been many suggestions about what sort of human social relationships could be eventually replaced by human-robot relationship, the complex social behavior of humans seems to hinder the construction of a robotic partner that displays competent social behavior. The lack of recognizing relation-specific social behavior has led to discussions, whether social robots should be slaves, butlers or companions (see Wills, 2010). We suggest taking a look at another aspect of human history during which we shared our life with members of many other species. Such interactions may serve as behavioral models for a broad range of companion robots.

\section{HUMAN INTERACTION WITH ANIMALS}

Although the ethological definition of social behavior refers only to members of the same species (see above Székely et al., 2010), it is clear that in some situations social interactions occur between individuals of different species. Thus we may re-define social behavior without specifying the genetic relationship among the interacting individuals. In other words, interactions of both within and between species could be characterized as "social."

The idea of inter-specific social interactions can be applied to interactions between humans and their pet animals that have a long tradition in our history. The human attraction to animals in general has been discussed in terms of biophilia (see for example Wilson, 1984). One especially curious aspect of this human character is the keeping of pets that seems to be a universal trait of our species (Serpell, 1996; Podperscek et al., 2000). This tradition may have originated in hunter-gatherer societies that got in contact with the offspring of the species they had hunted for (e.g., Clutton-Brock, 1995). However, it is likely that even if these young individuals were tamed by early exposure to humans, they moved off or were eaten later. This type of pet keeping has survived in the Australian Aborigines who collect dingo puppies that live in the community for 1-2 years and return to their wild companions at maturity (for a review see Smith and Litchfield, 2009). The emergence of domesticated animals [specifically the dog, originating from around 25-30,000 years ago (e.g., Savolainen et al., 2002, but see also Davis and Valla, 1978), followed by the cat documented from 10,000 years ago - Vigne et al., 2004] has facilitated pet keeping habits in humans, and very likely these animals stayed for longer in the community sharing the life of their caregivers, and may have avoided being eaten. There is little evidence that such early pet keeping in archaic societies had some primary function (but see Serpell, 1996 for a collection of such ideas). Such habits may have been a by-product of the highly social nature of humans, especially of women and their children. Pet animals may have represented the first advanced "toys" for social interaction for children by which they improved their nursing and care taking skills.

In modern societies domesticated animals play different roles as pets. In more industrialized countries pets (mostly dogs) contribute to the secondary socialization of people who are ostracized from the society for shorter of longer periods, and thus experience a marked decrease in social contacts (e.g., homeless, hospitalized people). Many people who are or become lonely in the course of their life may also respond to the shortage of human social interaction by procuring a pet (e.g., single children, divorced people, widows; e.g., Albert and Bulcroft, 1988).

It seems that animals emerging in the human communities may provide a good model for a broad range of robotic companions. The fact that they have been present through most of the modern human history argues for some general function (see above), but there has been some suggestions for particular functions as well.

\section{ANIMALS AS MODELS OF COMPANION ROBOTS: SELECTED EXAMPLES}

There has always been some connection between robot building and our experiences with animals. Many researchers categorize robots as "zoomorphs" if they resemble a living, extant or imaginary animal species. For example, one of the first radio-controlled robots was designed and built in 1912 by John Hammond Jr. and Benjamin Miessner. Despite having a quite simple appearance, a box rolling on three wheels, the engineers named it "electric dog." Since then many hundreds of robots have been built which resembled animals in various ways. We review here only a few of those that have been built more recently and specifically for interacting with humans (see also Table 1).

Actually, there may be a clear functional argument for the construction of such robots because of their utility in providing social interaction for people in need. At present dogs and other animals are utilized for such interventions (e.g., animal assisted therapy, Odendall, 2000). However, such robots can have a clear advantage in some cases because they could be used easier in hospital 


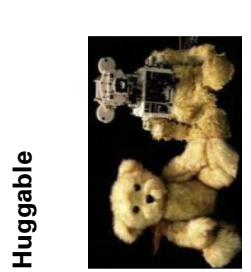

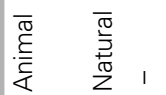

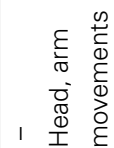

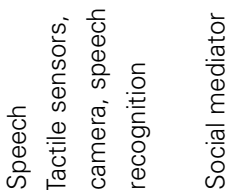

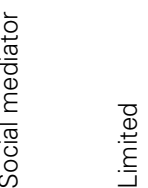

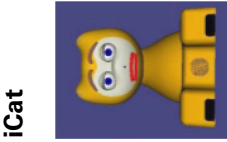

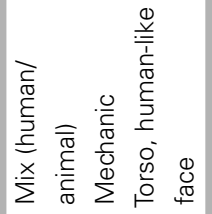

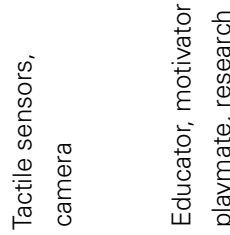

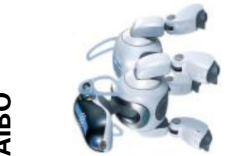

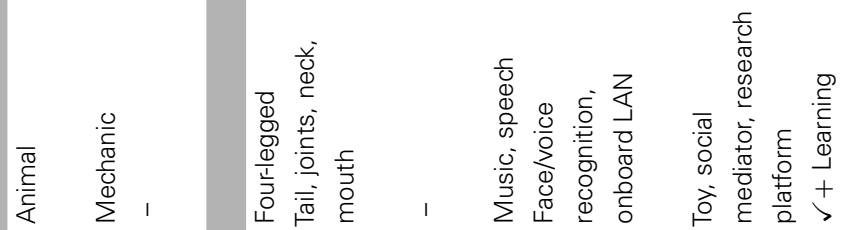

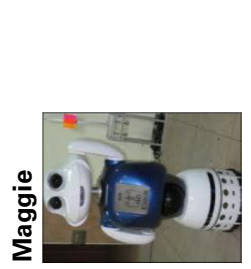

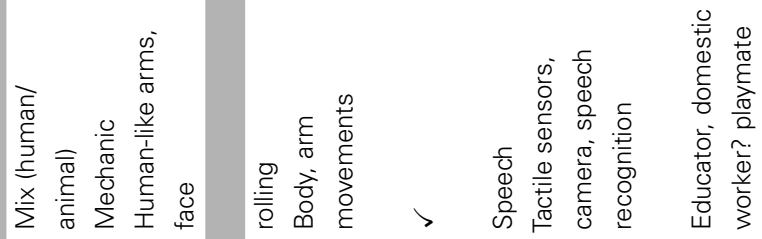

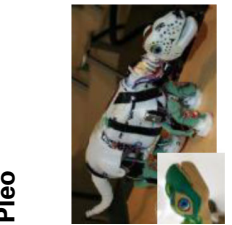

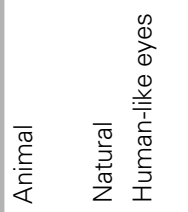

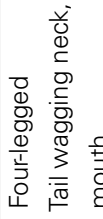

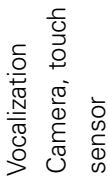

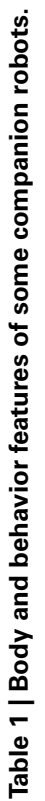

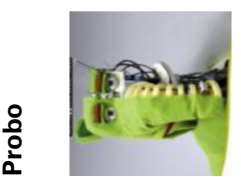

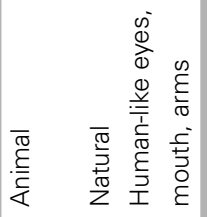

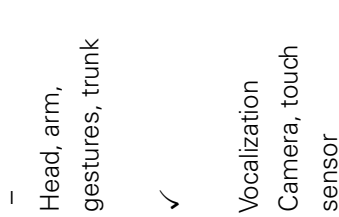

$\varepsilon$
$\frac{\varepsilon}{0}$
$+\frac{0}{0}$
$\frac{\pi}{0}$
$\frac{1}{0}$
$\frac{0}{\pi}$
0
0
0
$\simeq$

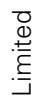

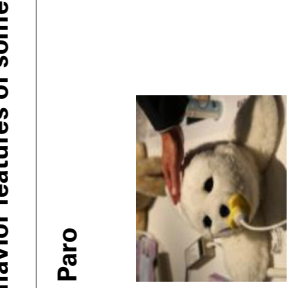

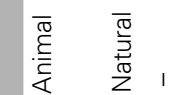

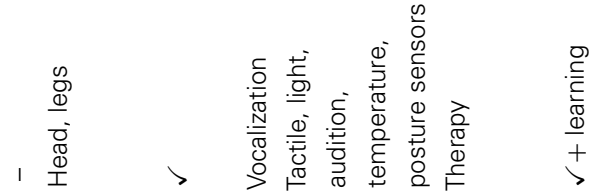

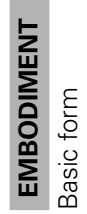

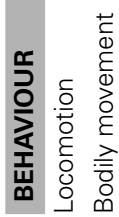

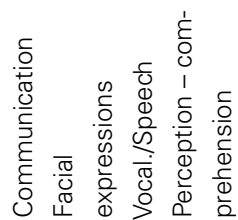

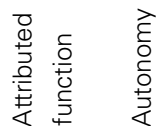


environment or with people who are sensitive for infections. Such robots can be more robust (work for extended time), and one could avoid issues of animal welfare. Thus in the long run such social robots would be cost effective. Indeed there are already examples in which such robots can be useful, for example, some researchers have utilized robots in training of autistic children (Dautenhahn and Werry, 2004; Prothmann et al., 2006).

The Paro robot was created by Shibata et al. (1997). The robot resembles a seal puppy both in appearance and behavior and was foreseen as having a therapeutic function. Seal puppies have large dark eyes that make an appealing contrast to their snowwhite fur. They move clumsily on land and emit high pitched calls to contact their mother. Paro is able to blink with the eyes, to respond by specific body movements to petting and is able to vocalize. Several commercial media news and research papers indicate that Paro is utilized successfully with hospitalized children or in homes for the elderly and in kindergartens (e.g., Kidd et al., 2006). The key to Paro's success is probably its simplicity and that the puppy-like appearance does not evoke unfounded expectancy from human users.

A relatively similar, more recent project by Saldien et al. (2008) has aimed at developing a more complex "huggable" robot named Probo for hospitalized children. This is a zoomorphic robot with a moveable trunk and ears on a relatively human-like face. Probo resembles a cartoon character designed for children, and utilizes many features that are appealing for them, including the "Kinderschema" (e.g., large eyes and head) applied also by Walt Disney in his cartoon figures. No applied study on the effectiveness of Probo is presently available. A very similar project is being carried out with a more human-like robot, Maggie (Salichs et al., 2006). The Pleo robot resembles a young dinosaur but its design concept is also based on cartoons. It has a huge head and eyes and is able to move its body parts (neck, tail, leg). In contrast to the stationary Paro and Probo, Pleo is also able to move slowly on the ground. The designers of Pleo emphasise its ability "to develop" into an individual creature (www.pleoworld.com). So far only a few experimental studies have looked at the interaction between people and Pleo, reporting mixed results (e.g., Dimas et al., 2010). It is not clear whether users do attribute those features to Pleo that were intended by the designers. Further, Pleo does not have any practical function, it represents a complex (and expensive) toy for children.

The designer of AIBO often claimed that they did not want to make a dog robot, nevertheless the embodiment and body ratio most closely resemble a small-sized dog, for example, a toy schnauzer. Moreover the behavior of the robot was explicitly modeled on the basis of canine behavior (Arkin, 2001) relying on a behavioral system approach championed by ethologists (e.g., Tinbergen, 1951; Timberlake, 1994). AIBO has very sophisticated motor skills, and a limited set of sensors (camera, microphone, sensors for touching), and could be trained for performing simple actions (Kaplan et al., 2002), and it could also learn by itself in a novel environment (Oudeyer et al., 2005). AIBO's design and features were improved over the years and it was also sold on the market with relatively good success (the production of AIBOs ended in 2006). Because of this it was also utilized in many research projects (see below).

\section{ETHOLOGY OF COMPANION ROBOTS}

At this point it is important to stress that companion robots designed so far have no function in the strict sense. For clarity one should distinguish between attributed function and realized function. The former refers to a function that exists in the mind of the researcher or developer, whilst the latter can only be proven by showing a clear advantage for the new agent over other existing agents in terms of functionality. In this regard scientific experiments signify only the first step (see below), and only widespread establishment ("survival") in the human community can eventually provide some evidence for function (e.g., according to this view mobile phones have a function). The production of companions without real functional challenges faces difficulties, and such situations usually lead to diverse approaches, which is nicely exemplified by the array of presently available companion robots. At the moment there seem to be no design rules for companion robots, researchers using a mixture of mechanism that is at their disposal (see Table 1). These range from relatively realistic copies to virtual, fictitious agents (c.f. hybrids from Greek - combining body parts of one or more animal species, e.g., centaurs).

\section{EMBODIMENT}

Although animals provide an inspiration for companion robots, most of these have some sort of human (or childish) features, like short arms, large head, and eyes with white sclera. This effort obviously mirrors the history of cartoons in which animal characters became more and more human-like over the last 100 years (e.g., Gould, 1980). While the Paro seems to be a nearly exact copy of the real animal (baby seal), the Probo, Pleo, and Maggie are clearly hybrids inspired by at least one animal species and human by often combining different morphological features instead of whole body parts. Note also that hybrids (in mythology) were combining the advantageous functions of both original creatures. For example, mermaids had a fishlike lower body and a human-like upper torso, and were able to swim as well as caring objects in their hands and communicate with humans. This, however, is often not the case in robotic hybrids. For example, their (human) arms are used only for gesturing (and not to carry or touching anything), and the trunk of the Probo is also used only for communicating emotions.

\section{BEHAVIOR}

Very often the behavior of the companion robots is not in line with their embodiment. At the extreme the iCat resembling a cat does not move at all (see Table 1). The movement capacities in terms of walking ("running") of the Pleo and the AIBO are also very limited. They move ahead much slower than the "real" animal creatures. Since movement in space and in relation to each other is crucial for meaningful social interactions, there should be a preference for rolling robots given the limits of present day technology.

Dautenhahn (2007) refers to autonomy as the agent having its own goals that emerge as the function of inner states (e.g., motivations, emotions; see also Ziemke, 2008). Goal directed behavior of the agent provides perhaps the best information about autonomy in the eyes of the observer (Bíró et al., 2007). Most of these companion robots show quite limited autonomy, that is, they do not give the impression to be self-propelled. Present day companion 
robots are also constrained both in having own goals or in fulfilling the goals of the human partner. For example, in most human - companion robot interactions robots seem to behave as if they had been programmed with very little attention toward the human partner (see next section). The cause for such limitation is obvious. Most companion robots lack the necessary sensors (perception/sensitivity) and reaction speed to be able to participate in the social interaction with the human in a natural way. Social interactions with these robots are possible only because humans (in the short run) show a high behavioral tolerance (which is rarely accounted for in the experiments on human-robot interaction). In contrast, real dogs were interested only for a very short time (few seconds) in an approaching AIBO (Kubinyi et al., 2004). Companion robots have also a very limited motor capacity (in terms of degrees of freedom), thus it is not surprising that for most social interactions either exchange of emotions (utilizing a human-inspired face on the robots) or some sort of linguistic communication is the preferred option.

\section{TESTING FOR UTILITY IN COMPANION ROBOTS: THE AIBO}

As indicated above the first hurdle for claiming a function is to pass appropriate testing under controlled conditions. Unfortunately, present authors have found it very difficult to reveal from the information provided by the constructors (e.g., scientific reports, home pages, freely available videos, etc.) whether any testing of a particular robot has been carried out, so we decided to refer only to those studies in which a companion robot was tested by other research groups. A short non-exhaustive survey of such peer-reviewed publications revealed that considerable corpus of data is available only in the case of the AIBO (see Table 2 for seven publications) in which behavioral data were collected by observing human-AIBO interactions. This may not be a coincidence because the AIBO was the first companion robot marketed around the world. Note however, that despite its success the company (SONY) stopped the production of these robot companions. Most studies focused on children, and in six out of seven the interactions covered only a limited period. Most studies used a control (live $\mathrm{dog}$ ), results however were very variable, and the presence or absence of difference between AIBO and the live dog depended on the type of the behavior measure used. It is more unfortunate, however, that the design and methodological problems of most studies did not allow for any strong conclusions to be drawn. Here we list only a few of these issues in order to facilitate refinements in future designs. (1) Most observations were constrained to a single exposure in spite of the fact that the real utility of such robots would be in the long run. One may expect rapid habituation over time which may compromise the utility of such invention. (2) Little effort was taken to control for differences in the form and behavior of the two agents (live dog vs. AIBO), and in most cases the behavior of the AIBO (and the dog) was not reported. Thus any difference in the nature of interactions could be attributed to differences in behavior or other conditions (for example the AIBO was placed on a table vs. the dog was on the floor). (3) Little care was taken to control for differences in familiarity and

Table 2 | Overview of selected studies that investigated behavioral interaction with AIBO.

\begin{tabular}{|c|c|c|c|c|c|c|c|}
\hline & $\begin{array}{l}\text { Subjects, } \\
\text { status }\end{array}$ & Type & $\begin{array}{l}\text { Number of } \\
\text { exposures } \\
\text { (duration) }\end{array}$ & $\begin{array}{l}\text { Control } \\
\text { live dog }\end{array}$ & $\begin{array}{l}\text { Behavior } \\
\text { of AIBO\# }\end{array}$ & $\begin{array}{l}\text { Behavior } \\
\text { difference }\end{array}$ & $\begin{array}{l}\text { Overall } \\
\text { finding }^{\&}\end{array}$ \\
\hline $\begin{array}{l}\text { Kerepesi et al. } \\
(2006)\end{array}$ & $\begin{array}{l}\text { Children } \\
\text { (6-8 years), } \\
\text { typical }\end{array}$ & $\begin{array}{l}\text { Behavioral } \\
\text { interaction }\end{array}$ & 1 (5 min) & Dog puppy & $\begin{array}{l}\text { Basic }+ \text { ball } \\
\text { play }\end{array}$ & Yes & $\mathrm{Dog}>\mathrm{AlBO}$ \\
\hline $\begin{array}{l}\text { Melson et al. } \\
\text { (2009) }\end{array}$ & $\begin{array}{l}\text { Children } \\
\text { (7-15 years), } \\
\text { typical }\end{array}$ & $\begin{array}{l}\text { Behavioral } \\
\text { interaction }\end{array}$ & 1 (5 min) & Large-sized dog & Basic? & Yes & $\mathrm{Dog}=\mathrm{AIBO}$ \\
\hline $\begin{array}{l}\text { Okita and } \\
\text { Schwartz } \\
\text { (2006) }\end{array}$ & $\begin{array}{l}\text { Children } \\
\text { (3.5-5.5 years), } \\
\text { typical }\end{array}$ & $\begin{array}{l}\text { Behavioral } \\
\text { interaction }\end{array}$ & 1 (10-15 min) & No control & $\begin{array}{l}\text { AlBOs: Dance, } \\
\text { Kick stand }\end{array}$ & Yes & $\begin{array}{l}\text { Children attributed } \\
\text { differences }\end{array}$ \\
\hline $\begin{array}{l}\text { Kahn et al. } \\
\text { (2006) }\end{array}$ & $\begin{array}{l}\text { Children } \\
\text { (3-6 years), } \\
\text { typical }\end{array}$ & $\begin{array}{l}\text { Behavioral } \\
\text { interaction }\end{array}$ & 1 ( 15 min) & $\begin{array}{l}\text { No, stuffed dog } \\
\text { used }\end{array}$ & Basic? & Yes & AIBO $>$ Stuffed dog \\
\hline $\begin{array}{l}\text { Ribi et al. } \\
\text { (2008) }\end{array}$ & $\begin{array}{l}\text { Children } \\
\text { (3-6 years), } \\
\text { typical }\end{array}$ & $\begin{array}{l}\text { Behavioral } \\
\text { interaction }\end{array}$ & 11 (5 min/trial) & Small-sized dog & $\begin{array}{l}\text { Basic? + ball } \\
\text { play }\end{array}$ & Yes & $\mathrm{Dog}>\mathrm{AlBO}$ \\
\hline $\begin{array}{l}\text { Pepe et al. } \\
\text { (2008) }\end{array}$ & Adults, typical & $\begin{array}{l}\text { "Blind" } \\
\text { interaction } \\
\text { through } \\
\text { computer }\end{array}$ & 1 (? min) & Small-sized dog & $\begin{array}{l}\text { Virtual } \\
\text { navigation in } \\
\text { maze }\end{array}$ & No & $\mathrm{Dog}=\mathrm{AlBO}$ \\
\hline $\begin{array}{l}\text { Kramer et al. } \\
\text { (2009) }\end{array}$ & $\begin{array}{l}\text { Adults with } \\
\text { dementia }\end{array}$ & $\begin{array}{l}\text { Behavioral } \\
\text { interaction }\end{array}$ & 1 (3 min) & Large-sized dog & Basic & Yes & $\mathrm{Dog}=\mathrm{AlBO}$ \\
\hline
\end{tabular}

\#It was often not clear from the report how the AIBO was programmed.

\& "Overall finding" aims to capture the main conclusion of the original authors. 
novelty. The novelty of the AIBO could be either attractive or evoke avoidance, and both may fade with repeated exposure. The familiarity with the dog can have the same effect because some humans find dogs intrinsically attractive while others may find it repulsive. Thus in a certain human sample the preference for the AIBO or the dog may emerge in either direction. (4) The participation of another human in the social interaction (e.g., the therapist) may actually "overshadow" the relatively small difference in the social effect between the AIBO and the dog. Thus compared to the large amount of interactions with the human partner, little room is left to differentiate interaction patterns displayed toward those other agents (AIBO and dog). Thus in this light the remark by Melson et al. (2009, p. 558) “These results suggest that properly used AIBO or other robotic pets of similar technological sophistication may be helpful to elicit or maintain children's social interactions." seems to be quite premature.

Instead of comparing the AIBO with a real dog, a more promising method could be to compare the effect of differently behaving or reacting AIBOs (Okita and Schwartz, 2006). In line with this Lee et al. (2006) have also found that humans can distinguish between "introvert" and "extrovert" AIBOs after having interacted with them. There is also a need for more long-term experiments (Kidd and Breazeal, 2008) in order to reveal the everyday utility of the robot and find out its constraints.

\section{DOGS AS PROTOTYPICAL COMPANIONS}

Dogs are the key representatives of pets. They were the first species joining human society probably following a long period of close co-habitation living in similar habitats (Coppinger and Coppinger, 2001). Recent research has established that as a result of the domestication process dogs are able to acquire a set of social skills that improve their chances to survive in human communities. Domestication has probably changed the behavior of dogs (as compared to the ancestor species, the wolf, see e.g., Kubinyi et al., 2007) at several levels of organization which affected physiological and behavioral functioning. There are several interpretations of behavioral differences between dogs and wolves. For example, Hare et al. (2002) have suggested that the cognitive machinery dealing with human communicative cues may have evolved special features in dogs, alternatively dogs living with humans may have a better chance to learn about human social cues (Udell et al., 2010). Non-cognitive theories suggests that dogs may have been selected for a specific preference for learning about human-based cues (Reid, 2009), or changes in general behavioral character (e.g., emotionality) may make dogs more effective in being attuned to human-based cues (Hare and Tomasello, 2005).

Topál et al. (2009) approached the problem from a different perspective. They argued that independently from the actual physiological or mental mechanisms dog behavior should function as a counterpart of the respective human skill. For example, if humans use gestural cues for communication then dogs should be able to rely on these cues up to a certain level of complexity. This approach interprets dog-human interaction in terms of social competence. In order to be successful, dogs had to achieve the minimum level of social competence that fits human expectations with respect to the socio-ecological niche shared by humans and dogs. For example, as mentioned above dogs were probably the first animal utilized as pets by children, and those pet dogs had to be small and docile (not aggressive), showing low reactivity to unexpected stimulation, etc. It seems dogs were successful to fill the niche of a pet. Much later in human history dogs become popular for helping in various human activities. For example, as a result of selective processes dogs acquired the necessary skills for pulling a heavily loaded sled over long distances under the guidance of the human team leader. Over the last 8-10,000 years human history offered many different functions ("social niche") for the dog, some of which required very special social skills but there was always a need for extensive social competence. Topál et al. (2009) defined this type of social competence as the "Dog behaviour complex" which evolved for matching in a restricted way the so called "Human behaviour complex" (Csányi, 2000). Both behavior complexes consist of behavioral traits and skills that tighten social relationships (e.g., attachment, Topál et al., 1998), increase synchronization, allow for complex ways of communicative exchanges (e.g., gestural communication, Lakatos et al., 2009), and support cooperative interactions (e.g., guide dogs for the blind, Naderi et al., 2001).

The matching of these behavior complexes can be illustrated by attachment behavior in dogs and humans. The role of attachment in humans has received a continuous interest in human psychology (e.g., Bowlby, 1972). There have been many discussions on its evolutionary function of decreasing the risk of predation on the offspring, increasing the chances for social learning, etc. Human life is continuously enriched by different attachment relationships from childhood through marriage until late in life, and the function of adult attachment is also linked to increased need of parental care (Immerman, 2003; Fraley et al., 2005). Attachment is characterized by specific behaviors including the avoidance of and protest at separation and the maintenance of social contact, especially in case of danger.

Recent research has discovered that dogs form an attachment relationship with their owners, which is functionally very similar to that of infants (Topál et al., 1998; Gácsi et al., 2001; PratoPrevide et al., 2003). In specific behavioral tests dogs show most of those behavioral analogs that emerge also between the infant and the mother. These include, for example, preference of the owner in challenging situations, enhanced contact seeking and greeting behavior, protesting at separation. Importantly, such attachment relationship does not emerge in wolves toward their caretakers despite being extensively socialized (Topál et al., 2005). The ability to develop an attachment relationship with humans may have been the acquired during domestication being advantageous for forming long-term social relationship with humans (for further discussion see Topál et al., 2009).

\section{WHY ARE DOGS A GOOD ANIMAL MODEL FOR ROBOTIC COMPANIONS?}

As noted above, the first electric robot was called "electric dog" which is a nice example of anthropomorphism in engineers. However, several laboratories have taken this metaphor more seriously. AIBO was built as a copy of real dogs and was aimed also for having similar functions, being a human pet. This effort met with variable success (see above), but in other cases researchers utilized a more restricted set of dog behaviors in the robot. For example, Jones et al. (2008) constructed a robot on a Roomba 
vacuum cleaner platform. This resembled very crudely a doglike creature and showed some dog-like behavior features upon confronting people (e.g., it had a tail that could be wagged and emitted barking or whining sounds). Already in 1985 Tachi et al. (1985) reported on a robot which was inspired by guide dogs for the blind. More recently, Nguyen and Kemp (2008) built a robot helping disabled people. They observed how well-trained assistant dogs help disabled people in various tasks and programmed the robot to execute the required actions in similar ways. The robot's embodiment does not resemble a dog, and uses an arm for actions that the dog executes by mouth. However, the robot can be commanded verbally, similarly to an assistant dog or a human assistant.

Based on the above analysis of companion robots and ethological insights of the human-dog relationship we offer a partly different perspective. Dogs may be preferred models for a range of robotic companions if researchers utilize a more abstract approach, or are able to make broader generalizations. Importantly, companion robots should not strive for being a kind of "super-dog." Instead, their design should be maximally functional and their behavior should reflect the specific aspects of the dog behavior complex (see above) that can emerge within the ranges of their functionality. Depending on their "job," companion robots should display only a subset of dog behaviors that suit best the actual social relationship. Such subsets of behavioral skills are relatively easy to accomplish, without the need to involve complex cognitive skills. For example, the majority of dog owners believe that their dog feels guilt upon disobeying a rule (e.g., eating food from the table). Recent studies did not find evidence of guilt in dogs (Horowitz, 2009; Hecht et al., 2012). However, dogs displayed these "guilty behaviors" quite regularly so the owners had enough reasons to make these anthropomorphic attributions. This suggests that a simple behavioral mechanism may create the perception in the observer. Thus "guilty behavior" in dogs and humans is controlled by different cognitive/social mechanisms.

Considering the efficiency and believability of a social interaction between robot and man, it is not essential that the robot has the underlying cognitive capacity for a particular skill but rather that it should appear to have it. Accordingly, it may be enough for a better social understanding if the user attributes guilty behavior to a robot, even if guilt is not represented in the robot's cognitive machinery. Naturally, a deeper knowledge on the subtle details of behavioral interactions is unavoidable. So more ethologically inspired research is called for.

We note that similar inspiration may be gained from other human-animal interactions involving cats or horses. Such insights may be useful for designing specific types of companion robots, but they lack the generality and wide scale of human-dog interaction.

\section{REFERENCES}

Albert, A., and Bulcroft, K. (1988). Pets, families, and the life course. J. Marriage Fam. 50, 543-552.

Arkin, R. C. (2001). "Ethological modeling and architecture for an entertainment robot," in 2001
IEEE International Conference on Robotics and Automation, Seoul, 453-458.

Barrett, L., Henzi, P., and Rendall, D. does social complexity really require cognitive complexity? Philos. Trans. (2007). Social brains, simple minds:

In summary, there is much to be learnt from the dogs about how they achieve a relatively complex level of social interaction with humans. This knowledge could be applied in future robots in various ways, and would probably lead to a greater acceptance of such robots by the human partners.

\section{CONCLUSIONS}

1. Social behavior has some general features shared by various species. This can provide the basis for inter-specific interactions which will depend on the overlap of human and animal social competencies.

2. There is an increased interest in building companion robots at present but most of them lack a clearly defined function, thus their design is arbitrary. We suggest that companion robots should be designed with a broad range of not necessarily sophisticated (human-like) social skills, which correspond to the expected function and the level of social interaction with humans.

3. Humans have been for long attracted to animals, they are utilized partly as an outlet for increased social needs. Thus such animals may provide a useful biological model for developing companion robots. Dogs are especially promising for inspiration because they share numerous social niches with humans.

4. It is very important, however, that companion robots should not be a copy of dogs (or other living creatures) but their behavior should delineate the general design features of social behaviors, which play an essential role in interactions that develop between dogs and humans.

Note: The recent use of "companion" in the English speaking countries may originate from "Metamorphosis" which is a second season episode of Star Trek: The Original Series first broadcast November 10, 1967. "The Companion" is a shimmering blob of sparking energy, and this entity brought the crew to a planet to keep his human prisoner/pet company. It turns out that the Companion is in love with that man, so after solving the language barriers by using brain waves, Captain Cirk tries to convince the Companion that she is not compatible with Cochrane (retrieved from http://en.wikipedia.org/wiki/Metamorphosis_Star_Trek:_The_ Original_Series.)

\section{ACKNOWLEDGMENTS}

This work was supported by the EU FP7 ICT-215554 LIREC. We are also grateful to anonymous referees for suggestions, which improved our manuscript and may have made it more accessible to readers with different scientific background. Gácsi, Márta received support from the Hungarian Academy of Sciences (MTA $01031)$.

R. Soc. Lond. B Biol. Sci. 362, 561-575.

Becker-Asano, C., Ogawa, K., Nishio, S., and Ishiguro, H. (2010). "Exploring the uncanny valley with geminoi dhi-1 in a real-world application," in Proceedings of IADIS International
Conference Interfaces and Human Computer Interaction, 121-128.

Bíró, S., Csibra, G., and Gergely, G. (2007). The role of behavioral cues in understanding goal-directed actions in infancy. Prog. Brain Res. 164, 303-322. 
Bowlby, J. (1972). Attachment. Middlesex: Penguin Book.

Clutton-Brock, J. (1995). "Origin of the dog: domestication and early history," in The Domestic Dog: Its Evolution, Behaviour and Interactions with People, ed. J. Serpell (Cambridge: Cambridge University Press), 7-20.

Coppinger, R. P., and Coppinger, L. (2001). Dogs. Chicago: University of Chicago Press.

Csányi, V. (2000). The "human behaviour complex" and the compulsion of communication: key factors in human evolution. Semiotica 128, 45-60.

Dautenhahn, K. (2007). Socially intelligent robots: dimensions of humanrobot interaction. Philos. Trans. R. Soc. Lond. B Biol. Sci.362, 679-704.

Dautenhahn, K., and Werry, I. (2004). Towards interactive robots in autism therapy: background, motivation and challenges. Pragmatics Cogn. 12, $1-35$.

Davis, S. J. M., and Valla, F. R. (1978). Evidence for domestication of the $\operatorname{dog} 12,000$ years ago in the Natufian of Israel. Nature 276, 608-610.

Dimas, J., Leite, J., Pereira, A., Cuba, P., Prada, R., and Paiva, A. (2010). "Pervasive pleo: long-term attachment with artificial pets," in Mobile HCI, Lisboa.

Fitch, W. T., Huber, L., and Bugnyar, T. (2010). Social cognition and the evolution of language: constructing cognitive phylogenies. Neuron 65 , 795-814.

Fong, T., Nourbakshsh, I., and Dautenhahn, K. (2003). A survey of social robots. Robot. Autonomous Syst. 42, 143-166.

Fraley, R. C., Brumbaugh, C. C., and Marks, M. J. (2005). The evolution and function of adult attachment: a comparative and phylogenetic analysis. J. Pers. Soc. Psychol. 89, 731-746.

Gácsi, M., Topál, J., Miklósi, Á., Dóka, A., and Csányi, V. (2001). Attachment behaviour of adult dogs (Canis familiaris) living at rescue centres: forming new bonds. J. Comp. Psychol. 115, 423-431.

Gould, S. J. (1980). The Panda's Thumb. W. W. Norton

Hare, B., Brown, M., Williamson, C., and Tomasello, M. (2002). The domestication of social cognition in dogs. Science 298, 1634-1636.

Hare, B., and Tomasello, M. (2005). Human-like social skills in dogs? Trends Cogn. Sci. 9, 405-454.

Hecht, J., Miklósi, Á., and Gácsi, M. (2012). Behavioral assessment and owner perceptions of "guilty" behavior in dogs. Appl. Anim. Behav. Sci. (in press).

Horowitz, A. (2009). Disambiguating the "guilty look": salient prompts to a familiar dog. Behav. Process. 81, 447-452.

Immerman, R. S. (2003). Perspectives on human attachment (pair bonding): Eve's unique legacy of a canine analogue. Evol. Psychol. 1, 138-154.

Jones, T., Lawson, S., and Mills, D. (2008). "Interaction with a zoomorphic robot that exhibits canid mechanisms of behaviour," in 2008 IEEE International Conference on Robotics and Automation, Pasadena, 2128-2133.

Kahn, P. H. Jr., Friedman, B., PérezGranados, D. R., and Freier, N. G. (2006). Robotic pets in the lives of preschool children. Inter. Stud. 7 , 405-436.

Kahn, P. H. Jr., Ishiguro, H., Friedman, B., Kanda, T., Freier, N. G., Severson, R. L., and Miller, J. (2007). What is a human? - Toward psychological benchmarks in the field of humanrobot interaction. Interact. Stud. 8 , 363-390.

Kanda, T., Nishio, S., Ishiguro, H., and Hagita, N. (2009). Interactive humanoid robots and androids in children's lives. Child Youth Envir. 19, 12-33.

Kaplan, F., Oudeyer, P.-Y., Kubinyi, E., and Miklósi, Á. (2002). Robotic clicker training. Rob. Auton. Sys. 38, 197-206.

Kerepesi, A., Kubinyi, E., Jonsson, G. K., Magnusson, M. S., and Miklósi, A. (2006). Behavioural comparison of human-animal (dog) and humanrobot (AIBO) interactions. Behav Proc. 73, 92-99.

Kidd, C. D., and Breazeal, C. (2008). "Robots at home: understanding long-term human-robot interaction," in IEEE/RSJ International Conference on Intelligent Robots and Systems, Nice, 3230-3235.

Kidd, C. D., Taggart, W., and Turkle, S. (2006). "A sociable robot to encourage social interaction among elderly," in Proceedings of the IEEE International Conference on Robotics and Automation, Orlando, 39723976.

Kramer, S. C., Friedmann, E., and Bernstein, P. L. (2009). Comparison of the effect of human interaction, AAT and AIBO-AT on long-term care residents with dementia. Anthrozoos 22, 43-57.

Kubinyi, E., Miklósi, Á., Kaplan, F., Gácsi, M., Topál, J., and Csányi, V. (2004). Social behaviour of dogs encountering AIBO, an animal-like robot in a neutral and in a feeding situation. Behav. Proc. 65 231-239.

Kubinyi, E., Virányi, Z., and Miklósi, Á. (2007). Comparative social cognition: from wolf and dog to humans. Comp. Cogn. Behav. Rev. 2, 26-46.

Lakatos, G., Soproni, K., Dóka, A., and Miklósi, Á. (2009). A comparative approach to dogs' (Canis familiaris) and human infants' comprehension of various forms of pointing gestures. Anim. Cogn. 12, 621-631.

Lee, K. M., Peng, W., Jin, S.-A., and Yan, C. (2006). Can robots manifest personality? An empirical test of personality recognition, social responses, and social presence in human-robot interaction. J. Comm. 56, 754-772.

MacDorman, K. F., and Ishiguro, H. (2006). The uncanny advantage of using androids in cognitive and social science research. Interact. Stud. 7, 297-337.

Melson, G. F. Kahn, P. H., Beck, A., and Friedman, B. (2009). Robotic pets in human lives: implications for the human-animal bond and for human relationships with personified technologies. J. Soc. Issues. 65 545-567.

Naderi, Sz., Miklósi, Á., Dóka, A. and Csányi, V. (2001). Co-operative interactions between blind persons and their dogs. Appl. Anim. Behav. Sci. 74, 59-80.

Nguyen, H., and Kemp, C. C. (2008). "Bio-inspired assistive robotics: service dogs as a model for humanrobot interaction and mobile manipulation," in 2nd IEEE RAS EMBS International Conference on Biomedical Robotics and Biomechatronics, Scottsdale, 542-549.

Odendall, J. S. J. (2000). Animal-assisted therapy: magic or medicine. J. Psychosom. Res. 49, 275-280.

Okita, Y. S., and Schwartz, D. L. (2006). Young children's understanding of animacy and entertainment robots. Int. J. Hum. Robot. 3, 393-412.

Oudeyer, P., Kaplan, F., Hafner, V. V., and Whyte, A. (2005). "The playground experiment: task-independent development of a curious robot," in Proceedings of the AAAI Spring Symposium on Developmental Robotics, Palo Alto, 42-47.

Pepe, A. A., Ellis, L. U. Sims, V. K., and Chin, M. G. (2008). Go, dog, go: maze training AIBO vs. a live dog, an exploratory study. Anthrozoos 21 , 71-83.

Podperscek, A. L. Paul, S. E., and Serpell, J. (eds). (2000). Companion Animals and Us. Exploring the Relationship between People and Pets. Cambridge: Cambridge University Press.

Prato-Previde, E., Custance, D. M., Spiezio, C., and Sabatini, F. (2003). Is the dog-human relationship an attachment bond? An observational study using Ainsworth's strange situation. Behaviour 140, 225-254.

Prothmann, A., Bienert, M., and Ettrich, C. (2006). Dogs in psychotherapy: effects on state of mind. Anthrozoos 19, 265-277.

Reid, P. J. (2009). Adapting to the human world: dogs' responsiveness to our social cues. Behav. Proc. 80, 325-333.

Ribi, F. N., Yokoyama, A., and Turner, D. C. (2008). Comparison of children's behaviour toward Sony's robotic dog AIBO and a real dog: a pilot study. Anthrozoos 21, 245-256.

Rose, R., Scheutz, M., and Schermerhorn, P. (2010). Towards a conceptual and methodological framework for determining robot believability. Interact. Stud. 11, 314-335

Saldien, J., Goris, K., Yilmazyildiz, S.,Verhelst, W., and Lefeber, D. (2008). On the design of the huggable robot Probo. J. Phys. Agents 2, 3-11.

Salichs, M. A., Barber, R., Khamis, A. M., Malfaz, M., Gorostiza, J. F., Pacheco, R., Rivas, R., Corrales, A., Delgado, E., and García, D. (2006). "Maggie: a robotic platform for human-robot social interaction," in IEEE Robotics, Automation and Mechatronics, Bangkok, 1-7.

Savolainen, P., Zhang, Y., Luo, J., Lundeberg, J., and Leitner, T. (2002). Genetic evidence for an east Asian origin of domestic dogs. Science 298, 1610-1613.

Serpell, J. (1996). In the Company of Animals: A Study of HumanAnimal Relationships. Cambridge: Cambridge University Press.

Shibata, T., Yoshida, M., and Yamato, J. (1997). Artificial emotional creature for human-machine interaction. IEEE Int. Conf. Syst. Man Cybern. 3, 2269-2274.

Smith, B. P., and Litchfield, C. A. (2009). A review of the relationship between Indigenous Australians, Dingoes (Canis dingo) and domestic dogs (Canis familiaris). Anthrozoös 22, 111-128.

Székely, T., Moore, A. J., and Komdeur, J. (2010). Social Behaviour: Genes, Ecology and Evolution. Cambirdge: Cambridge University Press.

Tachi, S., Tanie, K., Komoriya, K., and Abe, M. (1985). "Electrocutaneous communication in a guide dog robot (MELDOG)," in IEEE Transactions 
on Biomedical Engineering, Chicago, 461-469.

Timberlake, W. (1994). Behavior systems, associationism, and Pavlovian conditioning. Psychon. Bull. Rev. 1, 405-420.

Tinbergen, N. (1951). The Study of Instinct. Oxford: Clarendon Press.

Topál, J., Gácsi, M., Miklósi, Á., Virányi, Z., Kubinyi, E., and Csányi, V. (2005). The effect of domestication and socialization on attachment to human: a comparative study on hand reared wolves and differently socialized dog puppies. Anim. Behav. 70, 1367-1375.

Topál, J., Miklósi, Á., Dóka, A., and Csányi, V. (1998). Attachment behavior in dogs (Canis familiaris): a new application of Ainsworth's (1969) strange situation test. J. Comp. Psychol. 112, 219-229.

Topál, J., Miklósi, Á., Gácsi, M., Dóka, A., Pongrácz, P., Kubinyi, E., Virányi, Z., and Csányi, V. (2009). The dog as a model for understanding human social behavior. Adv. Study Behav. 39, 71-116.

Udell, M. A. R., Dorey, N. R., and Wynne, C. D. L. (2010). What did domestication do to dogs? A new account of dogs' sensitivity to human actions. Biol. Rev. 85, 327-345.

Vigne, J. D., Guilaine, J., Debue, K.. Haye, L., and Gérard, P. (2004). Early taming of the cat in Cyprus. Science 304, 259.
Wills, Y. (ed.). (2010). Close Engagements with Artificial Companions: Key Social, Psychological, Ethical and Design Issues. Amsterdam: John Benjamins Publishing Company.

Wilson, E. O. (1984). Biophilia. Cambridge: Harvard University Press.

Ziemke, T. (2008). On the role of emotion in biological and robotic autonomy. BioSystems 91 401-408.

Conflict of Interest Statement: The authors declare that the research was conducted in the absence of any commercial or financial relationships that could be construed as a potential conflict of interest.
Received: 23 December 2011; paper pending published: 25 January 2012; accepted: 29 February 2012; published online: 19 March 2012.

Citation: Miklósi Á and Gácsi M (2012) On the utilization of social animals as a model for social robotics. Front. Psychology 3:75. doi: 10.3389/fpsyg.2012.00075

This article was submitted to Frontiers in Comparative Psychology, a specialty of Frontiers in Psychology.

Copyright (c) 2012 Miklósi and Gácsi. This is an open-access article distributed under the terms of the Creative Commons Attribution Non Commercial License, which permits non-commercial use, distribution, and reproduction in other forums, provided the original authors and source are credited. 